\title{
Carbon tetrachloride-induced hepatotoxicity in pregnant and lactating rats
}

\author{
Masahiro Mochizuki, Satomi Shimizu, Yoshinaka Urasoko, Kazuhiko Umeshita, \\ Takashi Kamata, Takahiro Kitazawa, Daichi Nakamura, Yoshito Nishihata, \\ Takumi Ohishi and Hiroshi Edamoto
}

\author{
Toxicology Department, Gotemba Laboratory, Bozo Research Center Inc., 1284 Kamado, Gotemba-shi, Shizuoka \\ 412-0039, Japan
}

(Received October 21, 2008; Accepted December 12, 2008)

\begin{abstract}
Carbon tetrachloride $\left(\mathrm{CCl}_{4}\right)$ is well known to induce hepatotoxicity after being metabolized to trichloromethyl free radical $\left(\cdot \mathrm{CCl}_{3}\right)$ by CYP2E1. In the present study, the hepatotoxicity induced by a single oral dose $(2,000 \mathrm{mg} / \mathrm{kg})$ of $\mathrm{CCl}_{4}$ was compared between pregnant (gestation days (GD) 13 and 19) or postpartum (postpartum days (PPD) 1,13 and 27) and non-pregnant rats. Hepatotoxicity in $\mathrm{CCl}_{4^{-}}$ treated pregnant rats evaluated by blood chemistry (alanine aminotransferase (ALT), aspartate aminotransferase (AST) and lactate dehydrogenase (LDH) activities) and histopathological finding (area of damaged hepatocytes) was minimal on GD19, being weaker than that in non-pregnant rats. CYP2E1 expression in non-treated pregnant rats decreased as pregnancy progressed and reached minimum level on GD19. Thus, the degree of $\mathrm{CCl}_{4}$-induced hepatotoxicity roughly corresponded to CYP2E1 levels during pregnancy. After delivery, hepatotoxicity in $\mathrm{CCl}_{4}$-treated lactating rats was maximal on PPD13, being stronger than that in non-pregnant rats, and then it decreased slightly on PPD27. The CYP2E1 level in the nontreated lactating rats tended to increase but remained at lower levels until PPD13 compared with that in non-pregnant rats. Thus, the degree of $\mathrm{CCl}_{4}$-induced hepatotoxicity did not correspond to CYP2E1 levels during lactation. This suggests that during lactation, there may be certain factors other than CYP2E1 expression responsible for the degree of $\mathrm{CCl}_{4}$-induced hepatotoxicity.
\end{abstract}

Key words: Carbon tetrachloride, Hepatotoxicity, Pregnancy, Lactation, CYP2E1, Rat

\section{INTRODUCTION}

During pregnancy, significant changes are observed in blood parameters in rats and rabbits as well as in women (Urasoko et al., 2008; Honda et al., 2008; de Rijk et al., 2002; Katoh et al., 1992; Wells et al., 1999). In addition, it is reported that total cytochrome P450 content and CYP3A and CYP2E1 expression levels decrease in the liver of pregnant rats (Dean and Stoch, 1975; Starkel et al., 2000), and that CYP2B1, CYP2B2, CYP2C6, CYP2E1 and CYP4A1 out of nine examined (CYP1A1, CYP2B1/CYP2B2, CYP2C6, CYP2C12, CYP2D1, CYP2D4, CYP2E1, CYP3A1 and CYP4A1) decrease during late pregnancy and early lactation in rats (He et al., 2005a, 2005b). These findings suggest that the mode of chemical-induced toxicity may probably be modified under pregnant and lactating conditions. For exam- ple, Carbon tetrachloride $\left(\mathrm{CCl}_{4}\right)$ is said to induce hepatic damage after being metabolized to trichloromethyl free radical $\left(\cdot \mathrm{CCl}_{3}\right)$ by CYP2E1 (Parkinson, 2001; Masuda, 2006), and CYP2E1 expression changes during gestation and lactation as mentioned above (He et al., 2005a, 2005b). Therefore, $\mathrm{CCl}_{4}$-induced hepatotoxicity seems to be modified in pregnant and lactating rats. The present study was carried out to examine this possibility.

\section{MATERIALS AND METHODS}

\section{Animals}

Male and female specific pathogen-free rats of the Sprague-Dawley strain (Crl:CD(SD), Atsugi Breeding Center, Charles River Japan Inc., Kanagawa, Japan) were mated at 11 to 12 weeks of age in our laboratory, and 40 pregnant rats were obtained. In addition, 8 non-pregnant

Correspondence: Masahiro Mochizuki (E-mail: mochizuki@bozo.co.jp) 
females (14-week-old) were used as controls.

As the $\mathrm{CCl}_{4}$-treated group, 25 pregnant rats and 5 nonpregnant rats at 14 weeks of age were used for blood chemistry and histopathological examinations. In addition, 15 out of the 25 pregnant rats and 3 out of 5 the nonpregnant rats were used for determining CYP2E1 expression. As the non-treated group, another 15 pregnant rats and 3 non-pregnant rats at 14 weeks of age were used for determining CYP2E1 expression during the pregnant and postpartum periods.

The animals were kept individually in a mesh cage in an air-conditioned animal room (temperature: $23 \pm 3^{\circ} \mathrm{C}$; humidity: $50 \pm 20 \%$; air ventilation: $10-15$ times/hr; lighting: 12-hr/12-hr light/dark cycle). Animals from mating to gestation days (GD)17 and from postpartum days (PPD)21 to PPD28 were housed individually in stainless steel wire mesh cages, and the animals from GD17 to PPD21 were housed individually with their litter in plastic cages with bedding. On PPD4, litter size was reduced to 8 pups ( 4 males and 4 females as far as possible) by random selection, and they were weaned on PPD21. The animals were allowed free access to pellet diet (NMF, Oriental Yeast, Co., Ltd., Tokyo, Japan) and tap water $a d$ libitum during the experimental period.

\section{Chemicals}

$\mathrm{CCl}_{4}$ and corn oil were purchased from Wako Pure Chemical Industries, Ltd. (Tokyo, Japan). $\mathrm{CCl}_{4}$ was dissolved in corn oil immediately before use, and the concentration was adjusted to $50 \mathrm{vol} \%$.

\section{Treatments}

For blood chemistry and histopathological examinations, 5 pregnant animals were orally administered a single dose $(2,000 \mathrm{mg} / \mathrm{kg})$ of $\mathrm{CCl}_{4}$ (Nagase and Tanaka, 1976) on GD12 and 18 and PPD0, 12 and 26, respectively. Five non-pregnant rats were also given a single oral dose $(2,000 \mathrm{mg} / \mathrm{kg})$ of $\mathrm{CCl}_{4}$ at the start of the experiment, and served as controls. Twenty-four hours after dosing, the animals were killed by exanguination from the abdominal aorta under ether anesthesia. As mentioned above, 3 treated and 3 non-treated pregnant animals were used for determining CYP2E1 expression by Western blotting on GD13 and 19 and PPD1, 13 and 27, respectively.

All procedures on this study were conducted in compliance with "Guidelines for Proper Conduct of Animal Experiments" (Science Council of Japan, June 1, 2006) and according to the Protocol approved by the Animal Care and Use Committee at BOZO Research Center Inc.. All efforts were made to minimize animal suffering.

\section{Blood chemical analysis}

Blood samples collected from the abdominal aorta under ether anesthesia were put into tubes (test tubes containing coagulation promoting agent, Venoject II-Autosep, Terumo Corporation, Tokyo, Japan). The samples were centrifuged (approximately $1,600 \times \mathrm{g}, 10 \mathrm{~min}$ ) to obtain sera, and alkaline phosphatase (ALP), triglyceride (TG), total cholesterol (T-CHO), total bilirubin (T-BIL) and phospholipids (PL) were measured using a clinical chemistry autoanalyzer, TBA-120FR (Toshiba Corporation, Tokyo, Japan).

Blood was also collected into heparinized test tubes (approximately 20 units of heparin per $1 \mathrm{ml}$ blood) and centrifuged (approximately $1,600 \times \mathrm{g}, 10 \mathrm{~min}$ ) to obtain plasma, and aspartate aminotransferase (AST), alanine aminotransferase (ALT) and lactate dehydrogenase (LDH) activities were measured using a clinical chemistry autoanalyzer, TBA-120FR.

\section{Histopathological examination}

The liver was excised from each animal at necropsy, and then fixed in phosphate-buffered $10 \%$ formalin. Four$\mu \mathrm{m}$ paraffin sections were stained with hematoxylin and eosin (H.E) for histopathological examination.

\section{Preparation of hepatic microsomes}

Liver microsomes were prepared for 3 pregnant and non-pregnant animals each of non-treated and $\mathrm{CCl}_{4}$-treated groups at necropsy as scheduled. The liver was excised from each animal at necropsy, perfused with $1.15 \% \mathrm{KCl}$ solution and frozen at $-80^{\circ} \mathrm{C}$ prior to microsomal preparation. Then the liver was thawed and homogenized with $1.15 \% \mathrm{KCl}$ solution to achieve a $25 \%$ homogenate. The homogenate was centrifuged at $9,000 \times \mathrm{g}$ for $20 \mathrm{~min}$. S9 was also prepared and centrifuged at $105,000 \times \mathrm{g}$ for 60 min to prepare a liver microsomal solution. Protein content was determined according to the method described by Lowry et al. (1951) using a spectrophotometer U-1100 (Hitachi, Ltd., Tokyo, Japan).

\section{Electrophoresis and Western blot analysis}

Protein concentration was adjusted for sodium dodecyl sulfate (SDS) / urea-polyacrylamide gel electrophoresis according to Laemmli (1970). Western blot analysis was performed using the techniques described by Kamata et al. (2005). Proteins were transferred onto polyvinylidene difluoride membranes (PVDF; Bio-Rad, Richmond, CA, USA) at $2 \mathrm{~mA} / \mathrm{cm}^{2}$ of constant current for $60 \mathrm{~min}$ and blocked for $1 \mathrm{hr}$ at room temperature in $4 \%$ Block Ace (Dainippon Sumitomo Pharma, Osaka, Japan). Membranes were hybridized with a primary CYP2E1 
$\mathrm{CCl}_{4}$-induced hepatotoxicity in pregnant and lactating rats

antibody (CHEMICON international, Inc., Temecula, CA, USA) diluted 500-times with 0.4\% Block Ace overnight and then with horseradish peroxidase (HRP)-conjugated secondary antibody (Kirkegaary \& Perry Laboratories, Inc., Gaithersburg, MD, USA) diluted 500-times with Tris buffered saline with Tween 20 (TTBS) for 8 hr. The membranes were incubated with 4-CN (4-chloro-1-naphthol, Wako Pure Chemical Industries, Ltd., Tokyo, Japan) to detect the proteins. Density of protein bands was calculated using the Scion (Scion Corporation, Frederick, MD, USA).

\section{Statistical analysis}

Significance of differences from the control group was tested after calculating Mean \pm S.D. in each group. Homogeneity of variance was assessed by Bartlett's test (Snedecor and Cochran, 1989). For homogeneous data (level of significance: 1\%, two-tailed), values were compared between the control group and each treated group by Dunnett's test (level of significance: 1 and 5\%, twotailed) (Dunnett, 1955, 1964).

\section{RESULTS}

\section{Blood chemistry findings}

Results of blood chemical analysis are shown in Table 1. In $\mathrm{CCl}_{4}$-treated groups, ALT activity on GD13 and 19 was 40 and 4\%, respectively, of that in non-pregnant animals. In addition, ALT activity on PPD1, 13 and 27 was 22, 119 and $35 \%$, respectively, of that in non-pregnant animals. AST activity on GD13 and 19 was 63 and 13\%, respectively, and that on PPD1, 13 and 27 was 101, 164 and $80 \%$, respectively, of that in non-pregnant animals. LDH activity on GD13 and 19 was 58 and 8\%, respectively, of that in non-pregnant animals. In addition, LDH activity on PPD1, 13 and 27 was 45, 98 and 32\%, respectively, of that in non-pregnant animals. As for other blood chemistry parameters examined in the $\mathrm{CCl}_{4}$-treated groups, there were no influences of pregnancy and lactation observed compared with non-pregnant animals.

\section{Histopathological findings}

$\mathrm{CCl}_{4}$-induced hepatic lesions were characterized by coagulation necrosis and/or vacuolation of hepatocytes mainly situated in the central to middle part of hepatic lobules (Fig. 1). In $\mathrm{CCl}_{4}$-treated non-pregnant animals, hepatic lesions were observed from central to middle parts of the hepatic lobule. In $\mathrm{CCl}_{4}$-treated pregnant animals, histopathological nature and degree of hepatic lesions on GD13 were equal to those in non-pregnant animals. On GD19, hepatic lesions were prominently reduced and limited to the central part of hepatic lobules. Hepatic lesions tended to increase again after delivery and became more marked than those in non-pregnant animals on PPD13. On PPD27, hepatic lesions, however, returned to almost the same degree as those in non-pregnant rats.

\section{Findings of Western blot analysis}

Results of Western blot analysis in non-treated groups are shown in Figs. 2 and 3. CYP2E1 expression in nontreated groups decreased as pregnancy progressed but it tended to increase after delivery. Specifically, CYP2E1 expression in pregnant animals on GD13 and GD19 was 68 and $30 \%$ of that in non-pregnant animals, respectively, and CYP2E1 expression in postpartum animals on PPD1, PPD13 and PPD27 was 72,78 and $112 \%$ of that in nonpregnant animals, respectively.

On the other hand, in $\mathrm{CCl}_{4}$-treated groups, CYP2E1

Table 1. Effects caused by single administration of $\mathrm{CCl}_{4}$ on blood chemistry parameters of pregnant and postpartum rats

\begin{tabular}{|c|c|c|c|c|c|c|c|}
\hline \multicolumn{2}{|c|}{ Parameter/Stage } & \multirow{2}{*}{$\begin{array}{c}\text { Control } \\
3968 \pm 3409\end{array}$} & \multirow{2}{*}{$\begin{array}{c}\text { GD13 } \\
1568 \pm 1833\end{array}$} & \multirow{2}{*}{$\frac{\text { GD19 }}{156 \pm 162^{*}}$} & \multirow{2}{*}{$\begin{array}{c}\text { PPD1 } \\
872 \pm 799\end{array}$} & \multirow{2}{*}{$\begin{array}{c}\text { PPD13 } \\
4720 \pm 3525\end{array}$} & \multirow{2}{*}{$\begin{array}{c}\text { PPD27 } \\
1400 \pm 901\end{array}$} \\
\hline ALT & $(\mathrm{IU} / \mathrm{l})$ & & & & & & \\
\hline AST & (IU/1) & $11224 \pm 6246$ & $7092 \pm 6184$ & $1425 \pm 1970$ & $11328 \pm 11613$ & $18444 \pm 8665$ & $9012 \pm 5227$ \\
\hline $\mathrm{LDH}$ & (IU/1) & $21556 \pm 21159$ & $12564 \pm 14562$ & $1650 \pm 3262$ & $9756 \pm 15645$ & $21164 \pm 18881$ & $6792 \pm 5552$ \\
\hline ALP & (IU/1) & $533 \pm 72$ & $586 \pm 129$ & $305 \pm 96$ & $337 \pm 156$ & $843 \pm 392$ & $551 \pm 151$ \\
\hline $\mathrm{TG}$ & $(\mathrm{mg} / \mathrm{dl})$ & $50 \pm 22$ & $66 \pm 71$ & $443 \pm 368^{* *}$ & $86 \pm 85$ & $112 \pm 88$ & $48 \pm 18$ \\
\hline $\mathrm{T}-\mathrm{CHO}$ & $(\mathrm{mg} / \mathrm{dl})$ & $47 \pm 10$ & $30 \pm 18$ & $63 \pm 24$ & $55 \pm 10$ & $74 \pm 14$ & $44 \pm 17$ \\
\hline PL & $(\mathrm{mg} / \mathrm{dl})$ & $91 \pm 18$ & $60 \pm 25$ & $154 \pm 70$ & $107 \pm 18$ & $136 \pm 42$ & $90 \pm 24$ \\
\hline T-BIL & $(\mathrm{mg} / \mathrm{dl})$ & $1.6 \pm 1.5$ & $0.28 \pm 0.3$ & $0.1 \pm 0.1^{*}$ & $0.3 \pm 0.2$ & $1.4 \pm 1.3$ & $0.2 \pm 0$ \\
\hline
\end{tabular}

The $\mathrm{CCl}_{4}$ level was set at $2,000 \mathrm{mg} / \mathrm{kg}$.

Each value represents the mean \pm S.D. of 5 female rats.

${ }^{*} \mathrm{p}<0.05,{ }^{* *} \mathrm{p}<0.01$ : Significantly different from the control group mean (Dunnett's test).

Control: non-pregnant rats, GD 13 and 19: pregnant rats, PPD 1 and 13: lactating rats,

PPD27: post-lactating rats. 

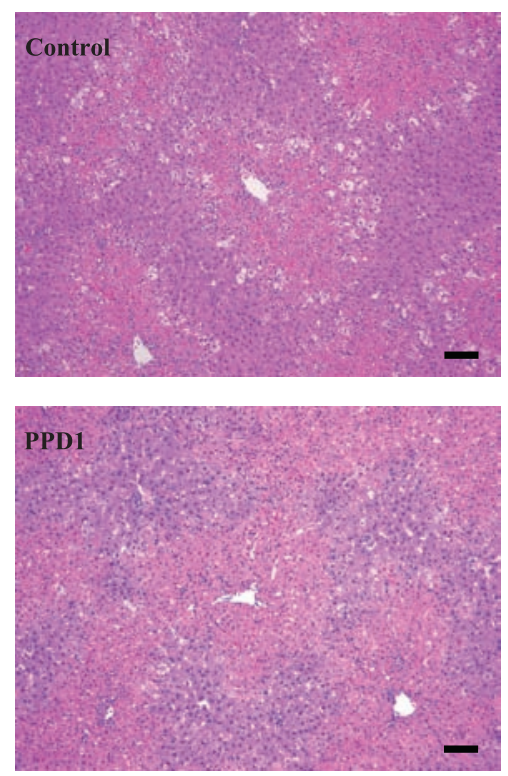
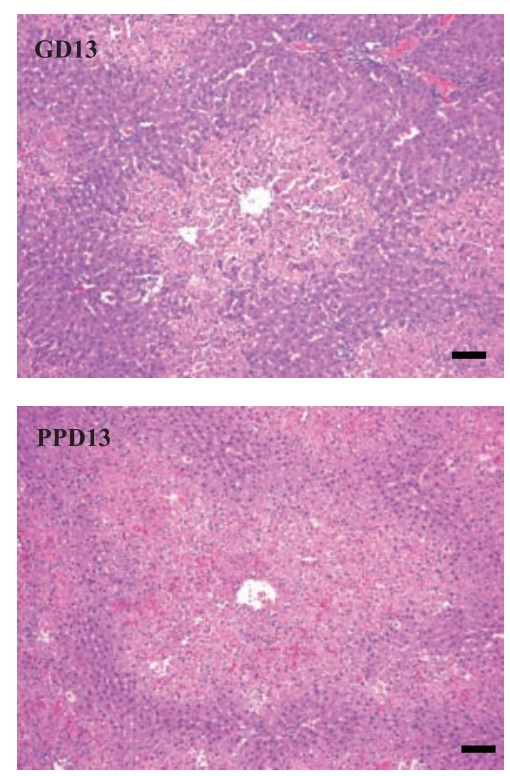
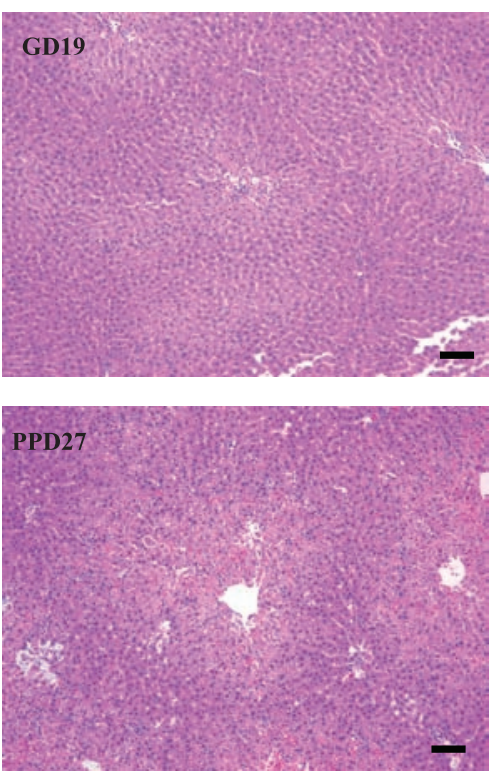

Fig. 1. Histopathological examination in the liver at $24 \mathrm{hr}$ after dosing of $\mathrm{CCl}_{4}$. Hematoxylin and eosin staining, magnification $\times 100$.

Control: non-pregnant rats, GD 13 and 19: pregnant rats, PPD 1 and 13: lactating rats, PPD27: post-lactating rats. $($ scale bar $=100 \mu \mathrm{m})$

expression in pregnant animals on GD13 and GD19 was 0.3 and $7 \%$, respectively, and that in postpartum animals on PPD1, PPD13 and PPD27 was $0.7,5$ and $0.4 \%$, respectively, compared with that in non-pregnant animals.

\section{DISCUSSION}

In this study, $\mathrm{CCl}_{4}$-induced hepatotoxicity was compared between pregnant or postpartum and non-pregnant rats.

Activities of AST, ALT and LDH as well as the extent of hepatic lesions were prominently reduced on GD19 when CYP2E1 expression showed the lowest level. Thus, the degree of $\mathrm{CCl}_{4}$-induced hepatotoxicity in pregnant animals seemed to roughly correspond to the expression level of CYP2E1 during pregnancy. CYP2E1 expression levels observed in the present study decreased along with the progression of pregnancy as reported previously (He et al., 2005a; Starkel et al., 2000). Dean and Stock (1975) suggested that lower levels of hepatic microsomal enzyme activity might reflect a biological control mechanism to ensure elevated levels of progesterone required to maintain pregnancy. Oxidative stress is said to decrease total CYP450 levels and drug-metabolizing activities in vivo (Liu et al., 1993), and He et al. (2005a) suggested that down-regulation of CYP2E1 levels during pregnan- cy observed in their study might be due to increased oxidative stress during pregnancy. Pahan et al. (1997) also demonstrated down-regulation of CYP2E1 expression in rat liver peroxisomes by ischemia/reperfusion-induced oxidative stress. In addition, it is known that endogenous nitric oxide (NO) production increases to maintain blood flow during pregnancy (Xu et al., 1996), and that endogenous NO also inhibits CYPs expression (Gonzalez, 1990; Khatsenko et al., 1997; Minamiyama et al., 1997). On the other hand, it has been documented that lipid peroxidation remains low until midpregnancy and begins to increase after GD15 in rats (Sugino et al., 1993), and as a protective factor against lipid peroxidation, superoxide dismutase (SOD) slightly increases in the liver of pregnant rats, but catalase and glutathione peroxidase (GSHPx) significantly decrease (Yoshioka, et al., 1987). In addition, Mover-Lev and Ar (1997) reported a decrease in GSH-Px in the liver and placenta of pregnant rats, and they suggested that oxidative stress might increase during pregnancy. These findings are considered to be attributable to the decreased CYP2E1 expression in pregnant rats observed in the present study.

Activities of ALT, AST and LDH as well as degree of hepatic lesions which decreased on GD19 compared with those in non-pregnant animals tended to be restored after delivery, and, on PPD13, activities of the above-men- 


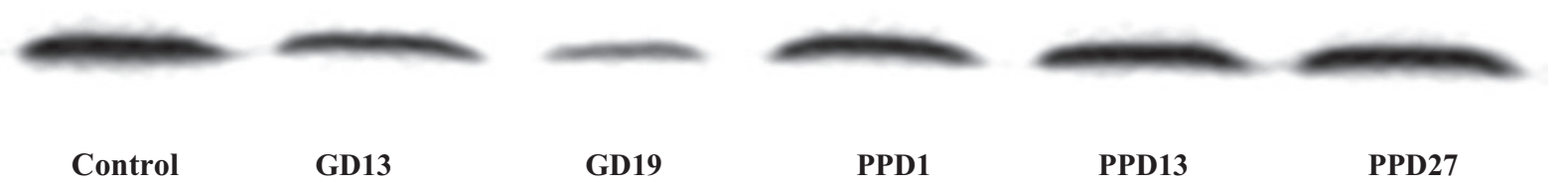

Fig. 2. CYP2E1 expressions by western blot analysis of liver microsomes from non-pregnant, pregnant, lactating and post-lactating rats.

Control: non-pregnant control, GD 13 and 19: pregnant rats, PPD 1 and 13: lactating rats, PPD27: post-lactating rats.

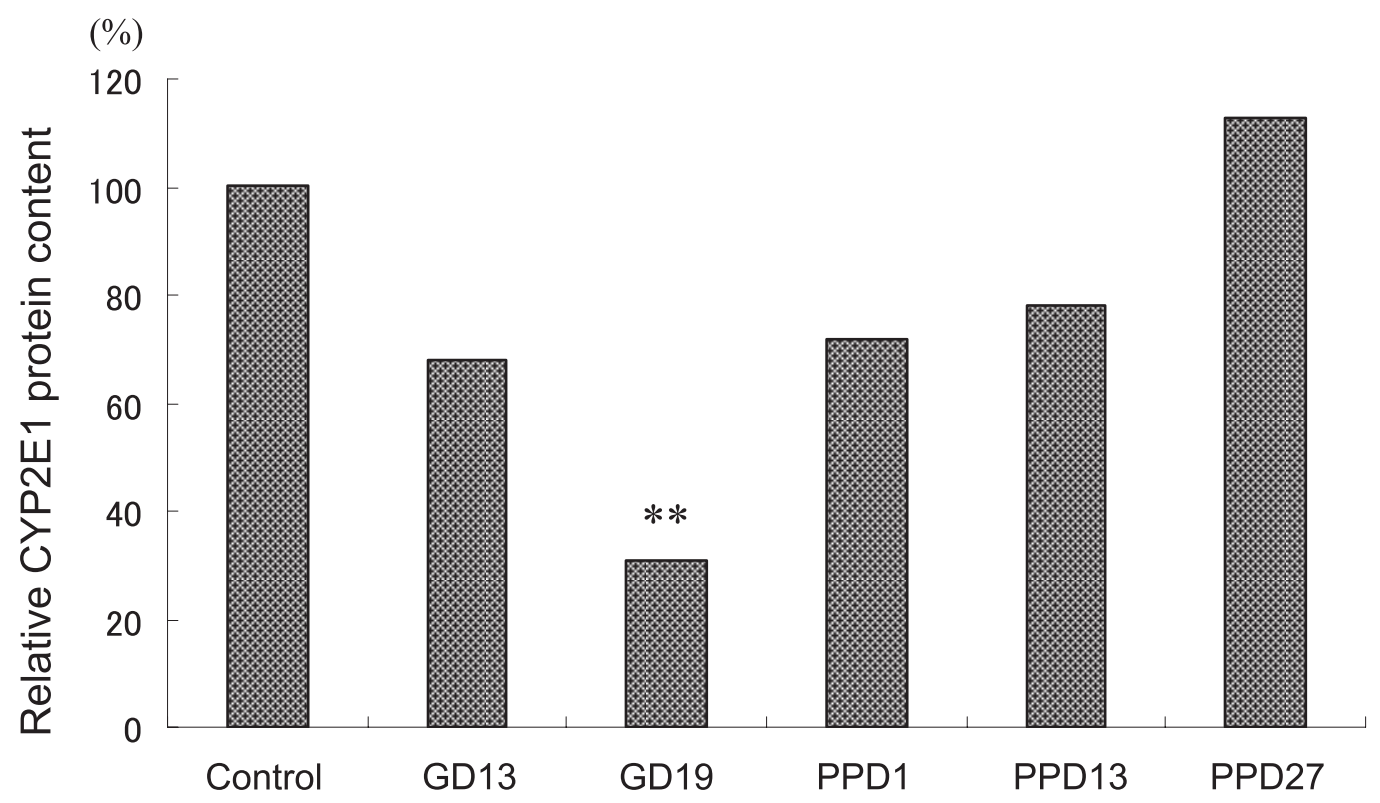

Fig. 3. The density of Western blotting using monoclonal antibodies against rat hepatic CYP2E1.

Each value represents the mean of three rats.

$* * p<0.01$ : Significantly different from the control group mean (Dunnett's test).

Control: non-pregnant rats, GD 13 and 19: pregnant rats, PPD 1 and 13: lactating rats, PPD27: post-lactating rats.

tioned enzymes were equal to or higher than those in non-pregnant animals. In addition, the degree of hepatic lesions was more marked than in non-pregnant animals. After that, the activities of the above-mentioned enzymes were lower than those in non-pregnant animals and the degree of hepatic lesions was equal to that in non-pregnant animals on PPD27. As to CYP2E1 expression, which tended to be restored after delivery, the levels still remained lower than that in non-pregnant animals until PPD13, and then returned to the level of non-pregnant animals on PPD27. Thus the degree of $\mathrm{CCl}_{4}$-induced hepatotoxicity did not correspond to the expression level of CYP2E1 after delivery. Papworth and Clubb (1995) reported that ALT, AST and ALP activities increased during the lactation period of rats, and they suggested that such changes might reflect an increase in hepatic metab- olism of dams in order to adapt themselves to increased food consumption/milk production for their pups. In addition, a study in ewes by El-Sherif and Assad (2001) showed that increases in AST and ALT activities reflected a state of hyperfunction during the lactation period, and another study in goats by Sarma and Ray (1985) showed that AST activity was high post partum and was positively correlated with milk yield. Moreover, Toropila et al. (2005) reported that activities of adaptive enzymes, ALT and AST, increased in hepatocytes of fasting rats due to endogenous synthesis of energy. Thus, the metabolic load on the liver increases in lactating animals compared with non-pregnant animals, and this may influence the mode of $\mathrm{CCl}_{4}$-induced hepatotoxicity during lactation.

GSH transportation to the mammary gland is essential to keep lactation, and the GSH released from the liver 
in lactating rats was higher than that in non-pregnant rats (Barber et al., 1999). On the other hand, decreased GSHrelease leaded to apotosis and involution of the mammary gland, and GSH synthesis in the liver decreased after the peak of lactation (PPD12 to 15) (Zaragozá et al., 2003, 2005). In addition, lipid peroxidation levels significantly increased in all major rat organs during the lactation period (Upreti et al., 2002). Therefore, changes in GSH and oxidative stress may also have a certain relation to the changes in $\mathrm{CCl}_{4}$-induced hepatotoxicity during lactation.

In conclusion, the present results strongly suggest that the mode of $\mathrm{CCl}_{4}$-induced hepatotoxicity in rats may be influenced by pregnancy and lactation.

\section{ACKNOWLEDGMENTS}

The authors would like to thank Dr. Kunio Doi, Emeritus Professor of the University of Tokyo, for reviewing this paper and Mr. Pete Aughton, D.A.B.T., Dip. R.C.Path., ITR Laboratories Canada Inc., for proofreading. In addition, the authors would like to thank Charles River Laboratories Japan, Inc. for their generous donation of experimental animals to support our study.

\section{REFERENCES}

Barber, T., Triguero, A., Martínez-López, I., Torres, L., García, C., Miralles, V.J., and Viña, J.R. (1999): Elevated expression of liver gamma-Cystathionase is required for the maintenance of lactation in rats. J. Nutr., 129, 928-933.

de Rijk, E.P., van Esch, E. and Flick, G. (2002): Pregnancy dating in the rat: Placental morphology and maternal blood parameters. Toxicol. Pathol., 30, 271-282.

Dean, M.E. and Stock, B.H. (1975): Hepatic microsomal metabolism of drugs during pregnancy in the rat. Drug Metab. Dispos., 3, 325-331.

Dunnett, C.W. (1955): A multiple comparison procedure for comparing several treatments with a control. J. Am. Stat. Assoc., 50, 1096-1121.

Dunnett, C.W. (1964): New tables for multiple comparison with a control. Biometrics, 20, 482-491.

El-Sherif, M.M. and Assad, F. (2001): Changes in some blood constituents of Barki ewes during pregnancy and lactation under semi arid conditions. Small Rumin. Res., 40, 269-277.

Gonzalez, F.J. (1990): Molecular genetics of the P-450 superfamily. Pharmacol. Ther., 45, 1-38.

He, X.J., Ejiri, N., Nakayama, H. and Doi, K. (2005a): Effects of pregnancy on CYPs protein expression in rat liver. Exp. Mol. Pathol., 78, 64-70.

He, X.J., Ejiri, N., Nakayama, H. and Doi, K. (2005b): Changes in cytochrome P450 isozymes (CYPs) protein levels during lactation in rat liver. Exp. Mol. Pathol., 79, 224-228.

Honda, T., Honda, K., Kokubun, C., Nishimura, T., Hasegawa, M., Nishida, A., Inui, T. and Kitamura, K. (2008): Time-course changes of hematology and clinical chemistry values in pregnant rats. J. Toxicol. Sci., 33, 375-380.
Kamata, T., Hiramoto, H., Morita N., Shen, J.R., Mann, N.H. and Yamamoto, Y. (2005): Quality control of Photosystem II: an FtsH protease plays an essential role in the turnover of the reaction center D1 protein in Synechocystis PCC 6803 under heat stress as well as light stress conditions. Photochem. Photobiol. Sci., 4, 983-990.

Katoh, M., Ozawa, M., Akima, T., Ikeda, H., Fujii, T. and Ishii, M. (1992): Hematological and serum biochemical changes with age in term fetuses, offspring and dams in normal Sprague-Dawley rats. Jikken Dobutsu, 41, 329-337.

Khatsenko, O.G., Boobis, A.R. and Gross, S.S. (1997): Evidence for nitric oxide participation in down-regulation of CYP2B1/2 gene expression at the pretranslational level. Toxicol. Lett., 90, 207-216.

Laemmli, U.K. (1970): Cleavage of structural proteins during the assembly of the head of bacteriophage T4. Nature, 227, 680685.

Liu, P.T., Kentish, P.A., Symons, A.M. and Parke, D.V. (1993): The effects of ether anaesthesia on oxidative stress in rats--dose response. Toxicology, 80, 37-49.

Lowry, O.H., Rosebrough, N.J., Farr, A.L. and Randall, R.J. (1951): Protein measurement with the Folin phenol reagent. J. Biol. Chem., 193, 265-275.

Masuda, Y. (2006): Learning toxicology from carbon tetrachlorideinduced hepatotoxicity. Yakugaku Zasshi, 126, 885-899.

Minamiyama, Y., Takemura, S., Imaoka, S., Funae, Y., Tanimoto, Y. and Inoue, M. (1997): Irreversible inhibition of cytochrome P450 by nitric oxide. J. Pharmacol. Exp. Ther., 283, 1479-1485.

Mover-Lev, H. and Ar, A. (1997): Changes in enzymatic antioxidant activity in pregnant rats exposed to hyperoxia or hypoxia. Comp. Biochem. Physiol., Part C: Toxicol. Pharmacol., 118, 353-359.

Nagase, S. and Tanaka, S. (1976): Chapter C-I-I Carbon tetrachloride. In Data of Clinical Biochemistry in Experimental Animal, pp.220-231, Soft Science, Inc., Tokyo.

Pahan, K., Smith, B.T., Singh, A.K. and Singh, I. (1997): Cytochrome P-450 2E1 in rat liver peroxisomes: downregulation by ischemia/reperfusion-induced oxidative stress. Free Radic. Biol. Med., 23, 963-971.

Papworth, T.A. and Clubb, S.K. (1995): Clinical pathology in the female rat during the pre- and postnatal preiod. Comp Haematol Int., 5, 13-24.

Parkinson, A. (2001): Chapter 6. Biotransformation of Xenobiotics. In Casarett and Doull's Toxicology: The Basic Science of Poisons, 6th ed. (Klaassen, C.D., ed.), pp.151-152, 188-191, McGraw-Hill., Now York.

Sarma, P.V. and Ray, T.K. (1984): Effect of physiological states on some blood enzyme levels and its relation to milk production. Indian J. Dary Sci., 38, 237-239.

Snedecor, G.W. and Cochran, W.G. (1989): Chapter 13, Analysis of variance: the random effects model. In Statistical Methods, $8^{\text {th }}$ ed., pp.251-252, Iowa State University Press, Iowa.

Starkel, P., Laurent, S., Petit, M., Van Den Berge, V., Lambotte, L. and Horsmans, Y. (2000): Early down-regulation of cytochrome $\mathrm{P} 4503 \mathrm{~A}$ and $2 \mathrm{E} 1$ in the regenerating rat liver is not related to the loss of liver mass or the process of cellular proliferation. Liver, 20, 405-410.

Sugino, N., Nakamura, Y., Takeda, O., Ishimatsu, M. and Kato, H. (1993): Changes in activities of superoxide dismutase and lipid peroxide in corpus luteum during pregnancy in rats. J. Reprod. Fertil., 97, 347-351.

Toropila, M., Nováková, J., Danŏvá, D., Paluchová, K., Kafka, I. and Lakticóvá, K. (2005): Changes in the activity of selected 
$\mathrm{CCl}_{4}$-induced hepatotoxicity in pregnant and lactating rats

adaptive enzymes in laboratory rats in relation to sex during prolonged fasting. Folia Veterinaria, 49 (Suppl. 3), 48-50.

Upreti, K., Chaki, S.P. and Misro, M.M. (2002): Evaluation of preoxidative stress and enzymatic antioxidant activity during pregnancy and lactation in rats. Health Popul., Perspect. Issues, 25, 177-185.

Urasoko, Y., He, X. J., Ebata, T., Kinoshita, Y., Kobayashi, J., Mochizuki, M. and Ikeya, M. (2008): Chenges in blood parameters and blood coagulation-related gene expression in pregnant rats. J. Am. Association for Laboratory Animal Science, In Press.

Wells, M.Y., Decobecq, C.P., Decouvelaere, D.M., Justice, C. and Guittin, P. (1999): Changes in clinical pathology parameters during gestation in the New Zealand white rabbit. Toxicol Pathol., 27, 3, 370-379.

Xu, D.L., Martin, P.Y., St. John, J., Tsai, P., Summer, S.N., Ohara,
M., Kim, J.K. and Schrier, R.W. (1996): Upregulation of endothelial and neuronal constitutive nitric oxide synthase in pregnant rats. Am. J. Physiol, 271, R1739-R1745.

Yoshioka, T., Motoyama, H., Yamasaki, F., Ando, M., Takahara, Y. and Yamasaki, M. (1987): Lipid peroxidation and vitamin E levels during pregnancy in rats. Biol. Neonate, 52, 223-231.

Zaragozá, R., García, C., Rus, A.D., Pallardó, F.V., Barber, T., Torres, L., Miralles, V.J. and Viña, J.R. (2003): Inhibition of liver trans-sulphuration pathway by propargylglycine mimics gene expression changes found in the mammary gland of weaned lactating rats: role of glutathione. Biochem. J., 373, 825-834.

Zaragozá, R., Miralles, V.J., Diana, R.A., García, C., Carmena, R., García-Trevijano, E.R., Barber, T., Pallardó, F.V., Torres, L. and Viña, J.R. (2005): Weaning induces NOS-2 expression through $\mathrm{NF}-\mathrm{KB}$ modulation in the lactating mammary gland: importance of GSH. Biochem. J., 391, 581-588. 